\title{
TITLE:
}

\section{Ion exchange in glass using femtosecond laser irradiation}

AUTHOR(S):

Kanehira, Shingo; Miura, Kiyotaka; Hirao, Kazuyuki

\section{CITATION:}

Kanehira, Shingo ... [et al]. Ion exchange in glass using femtosecond laser irradiation. APPLIED PHYSICS LETTERS 2008, 93(2): 023112.

\section{ISSUE DATE:}

2008-07-14

URL:

http://hdl.handle.net/2433/84594

\section{RIGHT:}

Copyright 2008 American Institute of Physics. This article may be downloaded for personal use only. Any other use requires prior permission of the author and the American Institute of Physics. 


\title{
lon exchange in glass using femtosecond laser irradiation
}

\author{
Shingo Kanehira, ${ }^{1, a)}$ Kiyotaka Miura, ${ }^{2}$ and Kazuyuki Hirao ${ }^{2}$ \\ ${ }_{1}^{1}$ Innovative Collaboration Center, Kyoto University, Nishikyo-ku, Kyoto 615-8510, Japan \\ ${ }^{2}$ Department of Material Chemistry, Graduate School of Engineering, Kyoto University, Nishikyo-ku, \\ Kyoto 615-8510, Japan
}

(Received 7 May 2008; accepted 26 June 2008; published online 16 July 2008)

\begin{abstract}
We explain the occurrence of ion exchange and an index profile around the focal point inside a commercial crown glass formed by femtosecond laser irradiation. The index profile in the photoinduced area has a ring-shaped pattern, which indicates that local densification occurred in the glass. An irregular surface reflecting the density distribution is formed around the focal point by dry etching process using a focused ion beam. By the irradiation of femtosecond laser pulses, the effect of ion exchange between the focal point and the surrounding area is also observed in the area in which local densification occurred. () 2008 American Institute of Physics.
\end{abstract} [DOI: $10.1063 / 1.2959820$ ]

Micromachining using femtosecond laser pulses has attracted considerable attention because it is extremely useful for the fabrication of waveguides, ${ }^{1,2}$ couplers, ${ }^{3}$ and microvoids ${ }^{4,5}$ and for the precipitation of gold nanoparticles ${ }^{6,7}$ inside transparent materials. When femtosecond laser pulses are focused inside glass or polymer via an objective lens, a photoinduced reaction occurs only near the focal point due to multiphoton absorption, resulting in a change in refractive index or the formation of microvoids at the focal point. In addition, when high-intensity laser pulses are focused inside specific transparent materials, filamentation is caused by nonlinear pulse propagation due to a dynamic competition between self-focusing and defocusing of electron plasma. ${ }^{8}$ In a previous paper, we have reported the spontaneous formation of a periodical array composed of nano-sized spherical voids in commercial borosilicate glass, under femtosecond laser irradiation at a low repetition rate of $1 \mathrm{kHz} .{ }^{9}$ This method can also be used to form dense dislocations with a cross-shaped pattern in a specific area in $\mathrm{MgO}$ single crystal. ${ }^{10}$ These formations are considered to be caused by shock waves near the focal point that is exposed to femtosecond laser pulses.

Femtosecond laser irradiation at a high repetition rate of over $\sim 200 \mathrm{kHz}$ tends to produce not only shock waves but also causes a heat accumulation effect around the focal point. ${ }^{11}$ Recently, it has been demonstrated that the latter is highly effective in writing a waveguide with a low optical attenuation ${ }^{12}$ and precipitating a $\beta-\mathrm{BaB}_{2} \mathrm{O}_{4}$ (Barium borate) crystal inside the glass. ${ }^{13}$ If heat transfer, also known as thermomigration, occurs inside the glass due to laser irradiation, the constituent elements of the glass will either disperse or agglomerate in a specific area because of the formation of a thermal gradient in a small area. Then, not only migration but also local distortion may occur. After the laser irradiation, the heated area in the glass is immediately quenched by rapid cooling. Investigating the relationship between ion behavior and the distortion is important for clarifying the reason for the change in refractive index or formation of voids

\footnotetext{
${ }^{a)}$ Author to whom correspondence should be addressed. Electronic mail: kane@collon1.kuic.kyoto-u.ac.jp. Tel./FAX: +81-75-383-2409/+81-75383-2410.
}

using the laser irradiation technique; however, this relationship has not yet been fully understood.

In this study, we analyzed the ion distribution in glass by using a dry etching process and an electron probe microanalyzer (EPMA). We found that when the laser pulses were focused tightly on the glass for a short time of $\sim 1 \mathrm{~s}$, some ions rapidly diffused away from the focal point, while others were concentrated around it.

In our experiments, we used commercially available synthetic crown glasses, S-1111 (Matsunami Co. Ltd., Japan), with dimensions of $5 \times 5 \times 0.9 \mathrm{~mm}^{3}$. Optical absorption measured with a spectrophotometer (JASCO V-570) was ignored in the wavelength range from $350 \mathrm{~nm}$ to $1 \mu \mathrm{m}$. The chemical composition of the glass samples was $\mathrm{Na}_{2} \mathrm{O}$ (9.25 wt \%), $\mathrm{SiO}_{2}\left(67.3\right.$ wt \%), $\mathrm{CaO}$ (7.21 wt \%), $\mathrm{K}_{2} \mathrm{O}$ (8.97 wt \%), and $\mathrm{ZnO}(4.14 \mathrm{wt} \%)$, as determined by $\mathrm{x}$-ray fluorescence analysis (Rigaku, x-ray spectrometer 3270). A regeneratively amplified $800 \mathrm{~nm}$ Ti:sapphire laser that emits $120 \mathrm{fs}, 200 \mathrm{kHz}$ (Coherent, Verdi) mode-locked pulses was used in our experiments. A laser beam, with a diameter of $5 \mathrm{~mm}$ in the Gaussian mode, was focused inside the glass sample using a water immersion objective lens $[63 \times$ magnification with a numerical aperture (NA) of 1.2] and a $x y z$ stage. $2.0 \times 10^{5}$ successive pulses were sharply focused inside the glass sample for $1 \mathrm{~s}$. The energy of each laser pulses was approximately controlled between 0.5 and $2.5 \mu \mathrm{J}$ by using a neutral density filter. To determine and visualize the distribution of ions and the change in refractive index after laser irradiation, we prepared a cross-sectional slice by etching with a focused ion beam (FIB) until the layer containing the focal point was exposed. The roughness of the exposed layer was characterized by atomic force microscopy (AFM) (SPI-4000). The distribution of the refractive index change around the photomodified area was analyzed using beam profile reflectometry. A field-emission EPMA (FE-EPMA: JXA-8500F) was used to visualize the existence and distribution of six ions ( $\mathrm{Si}, \mathrm{O}, \mathrm{Na}, \mathrm{K}, \mathrm{Zn}$, and $\mathrm{Ca}$ ) around the focal point.

Figure 1(a) shows AFM images of an area of 30 $\times 30 \mu \mathrm{m}^{2}$ captured after laser irradiation and dry etching with pulse energies of (i) $0.5 \mu \mathrm{J}$, (ii) $0.9 \mu \mathrm{J}$, and (iii) $1.3 \mu \mathrm{J}$. The black dots in Fig. 1(a) indicate a single void with a diameter of approximately $1 \mu \mathrm{m}$ at a depth of $500 \mathrm{~nm}$. It is 
(a)

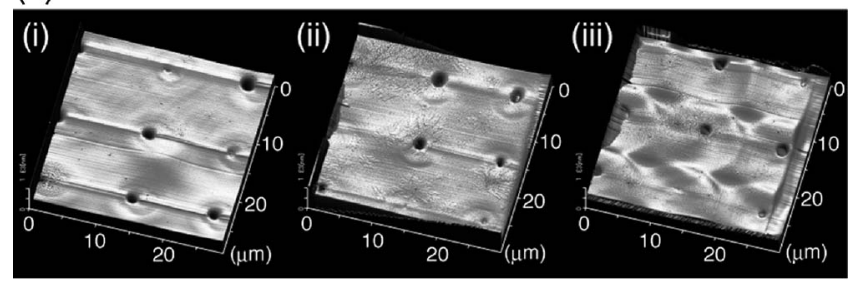

(b)

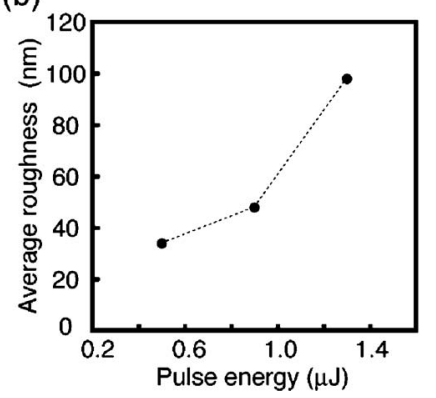

(c)

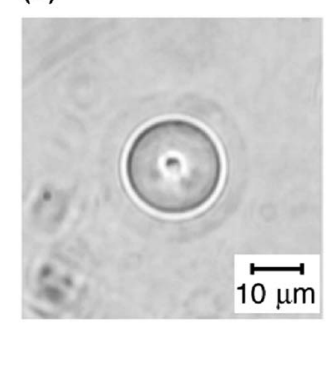

FIG. 1. (a) AFM image of the array of void in the area of $30 \times 30 \mu \mathrm{m}^{2}$ formed by femtosecond laser irradiation with a pulse energy of (i) $0.5 \mu \mathrm{J}$, (ii) $0.9 \mu \mathrm{J}$, and (iii) $1.3 \mu \mathrm{J}$ and successive FIB dry etching process, respectively. (b) Average roughness around the focal point as a function of pulse energy. (c) Top view optical microscope photograph around the focal point after femtosecond laser irradiation.

remarkable that some hollows having a diameter of 15-20 $\mu \mathrm{m}$, as shown in Fig. 1(a-iii) in particular, are clearly observed around each void. These hollows are caused by the difference in etching speed in a highly dense area, and they are responsible for the formation of an irregular surface. Figure 1(b) shows the average roughness of the exposed glass surface as a function of the focal pulse energy. The roughness increases dramatically when the pulse energy increases up to $1.3 \mu \mathrm{J}$ due to the formation of hollows, as shown in Fig. 1(a-iii). Figure 1(c) shows a top view optical microscope image captured after laser irradiation with a pulse energy of $2.0 \mu \mathrm{J}$. A white ring-shaped pattern with a diameter of $20 \mu \mathrm{m}$ which is caused by the change in refractive index, is clearly observed around the focal point. The ring area shares its boundary with the rough area shown in Fig. 1(a-iii). A detailed examination of $\mathrm{SiO}_{2}$ glass after femtosecond laser irradiation at a repetition rate of $1 \mathrm{kHz}$, which did not have a heat accumulation effect, was performed in Refs. 14 and 15. It is probable that the ring-shaped pattern is closely related to the local distortion of the glass sample, accompanied by the heat accumulation effect.

Figure 2 shows an index profile of the photomodified area around the focal point formed by laser irradiation with a pulse energy of $2.5 \mu \mathrm{J}$ and a $20 \times(\mathrm{NA}=0.4)$ objective lens. The top view optical microscope image of the area around the central dot is also shown in the same figure. The photomodified area contains a circular pattern with a different index profile. We classify this area into three sections; (a) a central black dot, (b) a white-ring area with a diameter of $\sim 20 \mu \mathrm{m}$, and (c) a gray-ring area with a diameter of $\sim 60 \mu \mathrm{m}$. The refractive index of (a) is less than 1.48, which is lower than that of the glass substrate (1.53). Section (b) has the highest refractive index of $\sim 1.56$ at the photomodified area. The refractive index of (c) is less than $\sim 1.54$, which is lower than that of (b). Briefly, the sections are arranged according to their refractive indices as follows: (b) $>(\mathrm{c})>(\mathrm{a})$. From the Lorentz-Lorenz formula, ${ }^{16}$ it is evident Downloaded 29 Jun 2009 to 130.54 .110 .22 . Redistribution subject

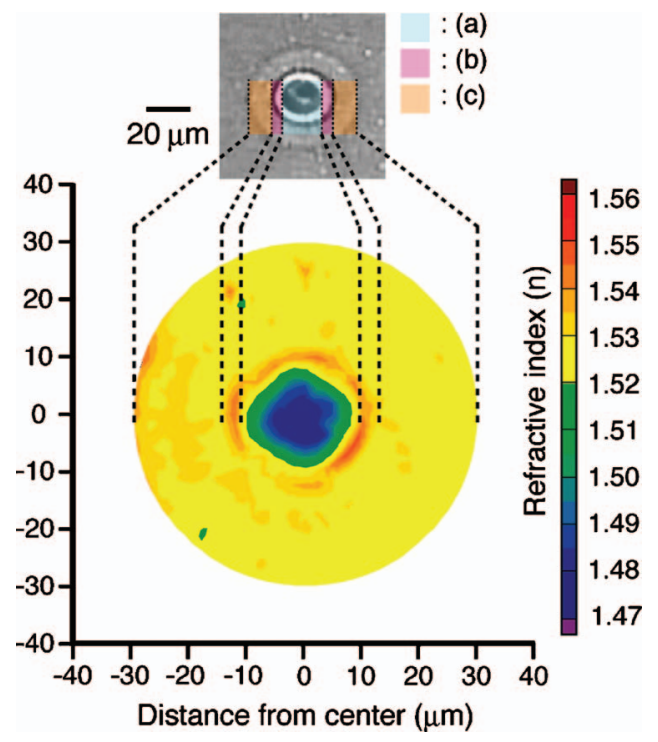

FIG. 2. (Color) Index profile around the focal point after femtosecond laser irradiation, measured using beam profile reflectometry. The inset at the top shows an optical microscope image of the measured area.

that the density of the glass is proportional to its refractive index. In our sample, there is a disparity of $1.7 \%$ between the highest and lowest densities calculated by this formula. These results indicate that the photomodified area has a concentric density profile after laser irradiation, which explains the formation of the inhomogeneous area due to femtosecond laser irradiation. The index profile of the photomodified area in $\mathrm{SiO}_{2}$ glass is shown in Ref. 14; however, the densified area is quite different in our study, probably due to the effect of another species except $\mathrm{Si}$ and $\mathrm{O}$ ions.

Figure 3(a) shows a profile of the ion concentration around the focal point after laser irradiation, as analyzed by FE-EPMA. The relative concentrations of $\mathrm{Si}^{4+}$ and $\mathrm{O}^{2-}$ ions (termed group I ions) increase and those of $\mathrm{K}^{+}, \mathrm{Na}^{+}, \mathrm{Ca}^{2+}$, and $\mathrm{Zn}^{2+}$ (termed group II ions) decrease at the focal point. However, in the area around the focal point, an opposite trend is observed. Figure 3(b) shows the results of a line-scan analysis of the relative atomic concentration across the focal point. The blue and yellow areas correspond to a circular area with a radius of $\sim 8 \mu \mathrm{m}$ and around the focal point with a radius of $\pm 10 \mu \mathrm{m}$, respectively. In the blue area, the concentrations of $\mathrm{Si}^{4+}$ and $\mathrm{O}^{2-}$ ions increase sharply to $\sim 17$ and 10 at $\%$, respectively, and the concentration of Group II ions, especially $\mathrm{K}^{+}$, decreases to $\sim 5$ at $\%$. In contrast, in the yellow area, the concentration of group I ions decreases to $\sim 5$ at $\%\left(\mathrm{Si}^{4+}\right)$, and that of group II increases to $\sim 2$ at $\%$ $\left(\mathrm{Na}^{+}\right)$. These results indicate that "ion exchange" effects might occur mainly between the blue and yellow areas in a very short time.

It is noteworthy that groups I and II have different ion distribution profiles, as shown in Figs. 3(a) and 3(b). This difference may be attributed to the behavior of each ion in the glass. Group I ions form the framework of the glass sample and group II provides additional oxygen ions that modify the network structure. Group I ions are generally known as network formers, while group II are known as network modifiers. The single-bond strength of the network formers $[\mathrm{Si}-\mathrm{O}(106 \mathrm{kcal} / \mathrm{g}$ atom $)]$ is much higher than that of the network modifiers [ $\mathrm{Zn}-\mathrm{O}(36 \mathrm{kcal} / \mathrm{g}$ atom), $\mathrm{Ca}-\mathrm{O}$ $(32 \mathrm{kcal} / \mathrm{g}$ atom $)$, and $\mathrm{K}-\mathrm{O}(13 \mathrm{kcal} / \mathrm{g}$ atom $)] .{ }^{17}$ Therefore, $(32 \mathrm{kcal} / \mathrm{g}$ atom $)$, and $\mathrm{K}-\mathrm{O}(13 \mathrm{kcal} / \mathrm{g}$ atom $)]$. Therefore,
AlP license or copyright; see http://apl.aip.org/apl/copyright.jsp 

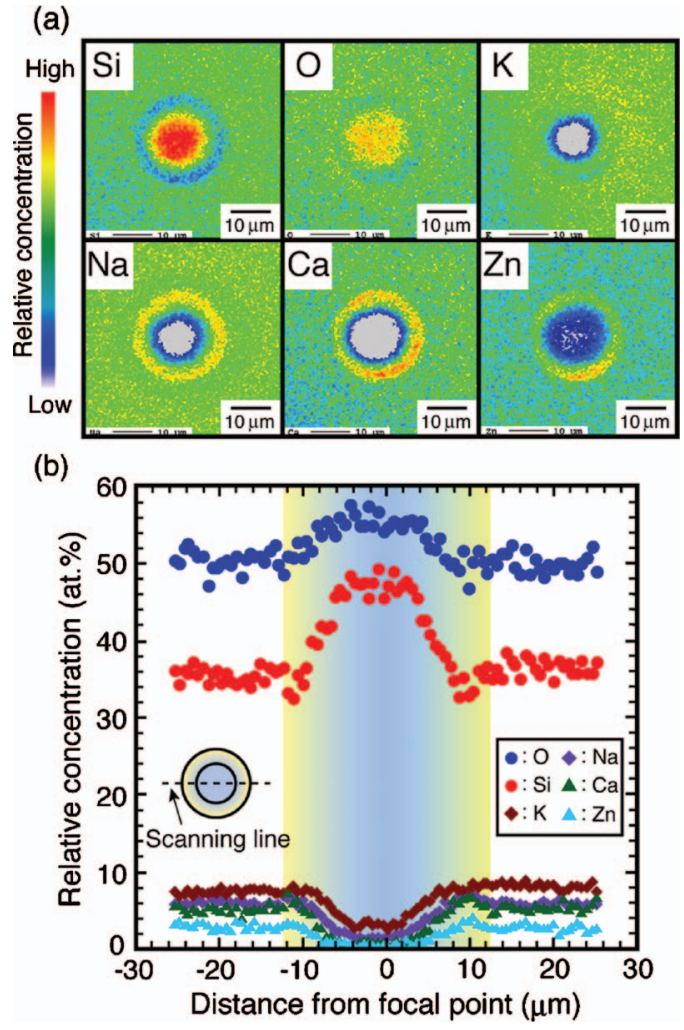

FIG. 3. (Color) (a) Ion distribution around the focal point after laser irradiation, as measured by EPMA. (b) Relative concentration profile of each ion across the photomodified area.

the bonds of the network modifiers will be easily broken, and each ion will diffuse away from the focal point.

Our group estimated that the temperature at the focal point exposed to a single femtosecond laser pulse with a pulse energy of $0.1 \mu \mathrm{J}$ would be higher than $3000 \mathrm{~K}$, which induces a pressure increase of $1 \mathrm{GPa}$ measured using a transient lens method with a time resolution of subpicoseconds. ${ }^{18}$ On the basis of this result, we speculated the possibility of changing the ring-shaped structure of the photoinduced area around the focal point by melting it. Koubassov et al. suggested the possibility of melting and subsequent structural change at the focal point in $\mathrm{SiO}_{2}$ glass during femtosecond laser irradiation. ${ }^{19}$ When the femtosecond laser beam was focused inside a glass, it ruptured at the focal point and transformed into a liquid state; then, all the bonds linking the metallic ions broke, resulting in the dispersion of the ions with a ring shape. In addition, diffusion classified as multicomponent diffusion occurred during laser irradiation because the sample glass contained many additional species classified as Group II ions. Since the diffusion coefficient of various modifiers (group II ions) was generally larger than that of the group I ions, group II ions diffused away from the laser-irradiated area due to the generation of shock waves and migrated out of the melting zone, thereby producing a ring. This process is schematically illustrated in Fig. 4.

In conclusion, we have demonstrated the ion exchange effect in glass after femtosecond laser irradiation. The glass

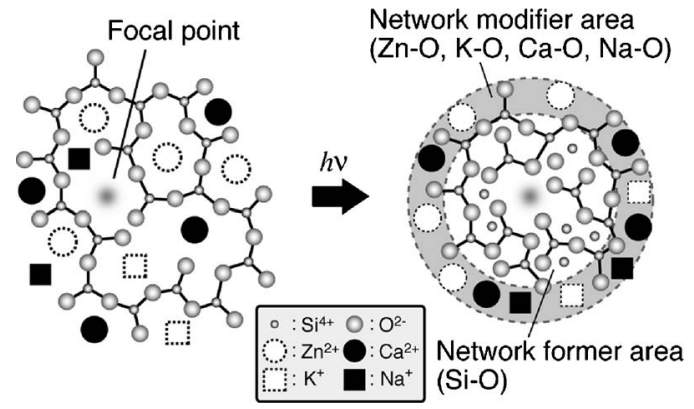

FIG. 4. Schematic illustration of the ion exchange process under femtosecond laser irradiation.

around the focal point has a ring-shaped structure, which indicates a high refractive index change. Ion exchange has also observed at the focal point in the glass between two groups of ions: network formers and network modifiers. The results of this study will be very important for writing a waveguide or a photonic device inside various types of glass.

The authors would like to thank Y. Shimotsuma and M. Sakakura from Kyoto University for discussions and supports, and also thank H. Honma and T. Yuasa from KRI, Inc. for technical supports. This research was supported by the Japan Securities Scholarship Foundation and the Grant-inAid for Young Scientists (B), 2007, No. 19760467.

${ }^{1}$ K. M. Davis, K. Miura, N. Sugimoto, and K. Hirao, Opt. Lett. 21, 1729 (1996).

${ }^{2}$ K. Miura, J. Qiu, H. Inouye, T. Mitsuyu, and K. Hirao, Appl. Phys. Lett. 71, 3329 (1997).

${ }^{3}$ A. M. Kowalevicz, V. Sharma, E. P. Ippen, J. G. Fujimoto, and K. Minoshima, Opt. Lett. 30, 1060 (2005).

${ }^{4}$ E. N. Glezer and E. Mazur, Appl. Phys. Lett. 71, 882 (1997).

${ }^{5}$ E. N. Glezer, M. Milosavljevic, L. Huang, R. J. Finlay, T.-H. Her, J. P. Callan, and E. Mazur, Opt. Lett. 21, 2023 (1996).

${ }^{6}$ J. Qiu, M. Shirai, T. Nakaya, J. Si, X. Jiang, C. Zhu, and K. Hirao, Appl. Phys. Lett. 81, 3040 (2002).

${ }^{7}$ J. Qiu, X. Jiang, C. Zhu, M. Shirai, J. Si, N. Jiang, and K. Hirao, Angew. Chem., Int. Ed. 43, 2230 (2004).

${ }^{8}$ L. Sudrie, A. Couairon, M. Franco, B. Lamouroux, B. Prade, S. Tzortzakis, and A. Mysyrowicz, Phys. Rev. Lett. 89, 186601 (2002).

${ }^{9}$ S. Kanehira, J. Si, J. Qiu, K. Fujita, and K. Hirao, Nano Lett. 5, 1591 (2005).

${ }^{10}$ S. Kanehira, K. Miura, K. Fujita, K. Hirao, J. Si, N. Shibata, and Y. Ikuhara, Appl. Phys. Lett. 90, 163110 (2007).

${ }^{11}$ R. R. Gattass, L. R. Cerami, and E. Mazur, Opt. Express 14, 5279 (2006).

${ }^{12}$ S. M. Eaton, H. Zhang, P. R. Herman, F. Yoshino, L. Shah, J. Bovatsek, and A. Y. Arai, Opt. Express 13, 4708 (2005).

${ }^{13}$ K. Miura, J. Qiu, T. Mitsuu, and K. Hirao, Opt. Lett. 25, 408 (2000).

${ }^{14}$ N. T. Nguyen, A. Saliminia, S. L. Chin, and R. Vallee, Appl. Phys. B: Lasers Opt. 85, 145 (2006).

${ }^{15}$ A. Saliminia, N. T. Nguyen, S. L. Chin, and R. Vallee, J. Appl. Phys. 99, 093104 (2006).

${ }^{16} \mathrm{M}$. Born and E. Wolf, Principles of Optics, 6th ed. (Pergamon, New York, 1983), p. 88.

${ }^{17}$ W. D. Kingery, H. K. Bowen, and D. R. Uhlmann, Introduction to Ceramics (Wiley-Interscience, New York, 1976), Vol. 4, pp. 97-99.

${ }^{18}$ M. Sakakura and M. Terazima, Phys. Rev. B 71, 024113 (2005).

${ }^{19}$ V. Koubassov, J. F. Laprise, F. Theberge, E. Forster, R. Sauerbrey, B. Mueller, U. Glatzel, and S. L. Chin, Appl. Phys. A: Mater. Sci. Process. 79, 499 (2004). 